\title{
PENGARUH VARIASI KUAT ARUS PADA PENGELASAN BAJA AISI 1050 TERHADAP KARAKTERISTIK BAJA DENGAN MENGGUNAKAN METODE LAS SMAW DAN TIG
}

\author{
Rindam Pranata Manihuruk ${ }^{1}$, Mahadi.S.T.M.T. ${ }^{2}$ \\ Departemen Teknik Mesin, Fakultas Teknik, Universitas Sumatera Utara \\ Email: rindammanihuruk@gmail.com
}

\begin{abstract}
One of the metal joining techniques by welding is welding TIG (Tungsten Inert gas) and SMAW (Shild Metal Arc Welding). With this welding we can connect metals such as: Aluminum, Copper, Carbon Steel, and Stainless Steel. This study was conducted to determine the effect of welding defects by TIG and SMAW welding on mechanical properties, microstructure, and strength of welded joints on AISI 1050 Steel. Welding was carried out using tungsten AWS EWTh2 filler TG-S50 and E6013 electrodes, current strength $80 \mathrm{~A}, 100 \mathrm{~A}, 120 \mathrm{~A}$ with a connection of seam V 60o. The testing method used was a hardness test with the Brinell Hardness Tester method, a tensile test with a Tensile Tester, and a microstructure test with a Metallurgycal Microscope. The average results of the hardness test obtained the mechanical properties of AISI 1050 SMAW steel welding in the welding area with $E 6013$ electrodes at $80 \mathrm{~A}$ current variation is $127.82 \mathrm{BHN} ; 100 \mathrm{~A}$ is $139.61 \mathrm{BHN}$ and $120 \mathrm{~A}$ is $159.01 \mathrm{BHN}$ and TIG welding with TG-S50 filer at $80 \mathrm{~A}$ current variation is $149.49 \mathrm{BHN} ; 100 \mathrm{~A}$ is $151.36 \mathrm{BHN}$ and $120 \mathrm{~A}$ is $164.44 \mathrm{BHN}$ from the above data. It is known that the greatest brinell hardness value is in the current variation of $120 \mathrm{~A}$ with a value of 159.01 BHN for SMAW welding with a value of 164.44 BHN for TIG. The TIG voltage value is a specimen with 120 A welding which is $628.93 \mathrm{~N} / \mathrm{mm} 2$ and the lowest is on the $80 \mathrm{~A}$ welding specimen of $566.53 \mathrm{~N} / \mathrm{mm} 2$ where the highest strain value is found in the current variation of $80 \mathrm{~A}$ with $4.8 \%$. And the highest voltage value in the SMAW welding is the $120 \mathrm{~A} / 602 \mathrm{~N}$ welded specimen which is $606 \mathrm{~N} / \mathrm{mm} 2$ and the lowest is the $80 \mathrm{~A}$ welding specimen at $501.33 \mathrm{~N} / \mathrm{mm} 2$ where the highest strain is in the current 120 A with 9.6 strain. The shape of the microstructure in AISI 1050 steel before welding is Feritte microstructure, in TIG welding the filler point and SMAW at the welding point (electrode) are cementite, and in the HAZ (Heat Affective Zone) area in both SMAW and TIG it has a microstructure that is the same as before welded namely feritte, but with different sizes
\end{abstract}

Keywords: TIG Welding, AISI 1050 Steel, Welding Defects Influencing Mechanical Properties, Strength of Welding Joints

\begin{abstract}
ABSTRAK
Salah satu teknik penyambungan logam dengan cara pengelasan adalah dengan pengelasan TIG (Tungsten Inert gas) dan SMAW (Shild Metal Arc Welding). Dengan las tersebut kita dapat menyambung logam seperti: Aluminium, Tembaga, Carbon Steel, dan Stainless Steel. Penelitian ini dilakukan untuk mengetahui pengaruh cacat las dengan pengelasan TIG dan SMAW terhadap sifat mekanik, struktur mikro, dan kekuatan sambungan las pada Baja AISI 1050. Pengelasan dilakukan dengan menggunakan tungsten AWS EWTh2 filler TGS50 dan elektroda E6013, kekuatan arus 80 A, 100 A,120 A dengan sambungan kampuh V $60^{\circ}$. Metode pengujian yang dilakukan adalah uji kekerasan dengan metode Brinell Hardness Tester, uji tarik dengan Tensile Tester, dan uji struktur mikro dengan Metallurgycal Microscope. Hasil rata-rata dari uji kekerasan didapat Sifat mekanik baja AISI 1050 las SMAW pada daerah las dengan elektroda E 6013 pada variasi arus $80 \mathrm{~A}$ adalah 127,82 BHN ; 100 A adalah 139,61 BHN dan 120 A adalah 159,01 BHN dan las TIG dengan filer TG-S50 pada variasi arus 80 A adalah 149,49 BHN ; 100 A adalah 151,36 BHN dan 120 A adalah 164,44 BHN dari data di atas di ketahui bahwa nilai rata-rata kekerasan brinell terbesar terdapat pada variasi arus 120 A dengan nilai 159,01 BHN untuk pengelasan SMAW dengan nilai 164,44 BHN untuk TIG. Nilai tegangan TIG adalah spesimen dengan las 120 A yaitu sebesar $628,93 \mathrm{~N} / \mathrm{mm}^{2}$ dan sebaliknya paling rendah adalah pada spesimen las 80 A sebesar $566,53 \mathrm{~N} / \mathrm{mm}^{2}$ dimana nilai regangan tertinggi terdapat pada variasi arus 80 A dengan 4,8\%.Dan nilai tegangan paling tinggi pada las
\end{abstract}


SMAW adalah spesimen dengan las 120 A yaitu sebesar $606 \mathrm{~N} / \mathrm{mm}^{2}$ dan sebaliknya paling rendah adalah pada spesimen las 80 A sebesar 501,33 N/mm² dimana regangan tertinggi terdapat pada arus 120 A dengan regangan 9,6. Bentuk struktur mikro pada baja AISI 1050 sebelum pengelasan adalah struktur mikro Feritte, pada pengelasan TIG dititik las (filler) dan SMAW di titik las (elektroda) adalah cementite, dan pada daerah HAZ (Heat Affective Zone) di SMAW maupun TIG memiliki struktur mikro yang sama dengan sebelum dilas yakni feritte, namun dengan ukuran yang berbeda

Kata kunci: Las TIG, Baja AISI 1050,Cacat las Berpengaruh Pada Sifat Mekanik, Kekuatan Sambungan Las

\section{I.PENDAHULUAN}

Saat ini teknik penyambungan logam di bidang pengelasan sudah berkembang pesat. Pada konstruksi yang menggunakan bahan baku logam, hampir sebagian besar sambungannya dikerjakan dengan cara pengelasan Contohnya ialah Shield Metal Arc Welding (SMAW) dan Tungsten Inert Gas (TIG) ${ }^{[1]}$

Perbedaan dari las TIG dan SMAW paling terlihat pada elektroda dan jenis pelindungnya ,elektroda pada las TIG yaitu tungsten tidak akan habis jika di gunakan karena logam pengisi pada las TIG adalah filler sedangkan pada las SMAW elektroda terbakar habis menjadi logam pengisi. Pada bagian pelindung las TIG menggunakan pelindung gas mulia yaitu $\operatorname{argon}(\mathrm{Ar})$ dan SMAW menggunakan flux yang terdapat pada elektroda ${ }^{[2]}$

Salah satu material yang banyak dipakai dalam pengelasan adalah baja, ada beberapa jenis baja yang dipakai, salah satunya adalah Baja AISI 1050. Baja AISI 1050 adalah baja karbon dengan paduan karbon 0,48\%-0,52\%. Baja spesifikasi ini banyak digunakan sebagai bahan tenik antara lain sebagai bahan komponen mesin. Oleh karena itu penulis ingin mengetahui kekuatan sambungan las dan sifat mekanik Baja AISI 1050 dengan las TIG dengan melakukan penelitian dan beberapa pengujian, seperti tensile test, hardness test, pengujian struktur mikro, dan uji NDT Radiography. Kemudian hasil analisa akan dibandingkan dengan spesimen tanpa dilas dengan pengujian yang sama.

\section{METODE}

Proses pengelasan dilakukan di Lab. Proses Produksi, Universitas Sumatera Utara dan pengujian tarik di lakukan di Lab. Material Test, Politeknik Teknologi Kimia Industri (PTKI),pengujian struktur mikro di Lab. Ilmu Logam Fisik Departemen Teknik Mesin USU,dan Pengujian radiografi dilakukan di Belawan oleh PT. Intergy Indonesia. Bahan yang di gunakan adalah Baja AISI 1050 dengan titik lebur 1401-1539 ${ }^{\circ} \mathrm{C}$, kekuatan tarik 580-750 MPa, dan komposisi kimia pada table 2.1. 
Tabel 2.1. Komposisi Kimia Baja AISI $1050^{[4]}$

\begin{tabular}{|l|c|}
\hline Unsur & kadar (\%) \\
\hline Iron, Fe & $98.46-98.92$ \\
\hline Manganese, Mn & $0.60-0.90$ \\
\hline Carbon, C & $0.470-0.55$ \\
\hline Sulfur, S & $\leq 0.050$ \\
\hline Phosphorous, P & $\leq 0.040$ \\
\hline
\end{tabular}

Baja AISI 1050 dilas dengan pengelasan TIG(Tungsten Inert Gas) menggunakan filler TG-S50 dan las SMAW menggunakan elektroda E6013, variasi arus 80A, 100A, dan 120A pengujian NDT (Non Destructive Test) radiografi dilakukan terlebih dahulu untuk mengetahui cacat yang terjadi dalam pengelasan TIG dan SMAW, spesimen uji kekerasan menggunakan standarisasi ASTM E 10 dan uji tarik menggunakan standarisasi ASTM E8

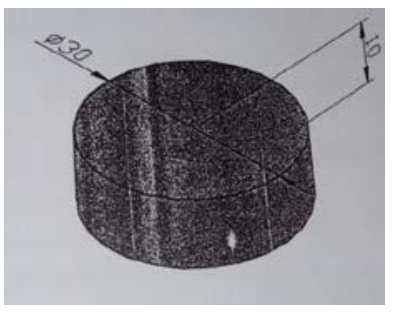

(a)

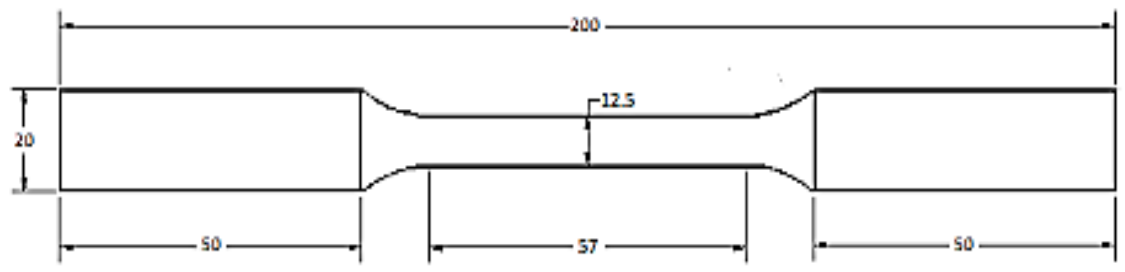

(b)

Gambar 2.1 Uji kekerasan ASTM E10 (a),Uji Tarik ASTM E8 (b) ${ }^{[4]}$

Pengujian Radiografi merupakan salah satu metode pengujian tak merusak dengan menggunakan sinar $\mathrm{x}$ atau sinar gamma untuk dapat melihat dan mengidentifikasi jenis cacat las. Non Destructive Tese (NDT) ${ }^{[3]}$

Uji kekerasan $^{[5]}$

Pengujian kekerasan dilakukan dengan metode brinel, dengan persamaan :

$$
B H N=\frac{P}{\frac{\pi \cdot D}{2}\left(D-\sqrt{\left.D^{2}-d^{2}\right)}\right.}
$$

Uji Tarik $^{[5]}$

$$
\begin{gathered}
\text { Tegangan (Stress) }: \sigma_{u}=\frac{F u}{A o} \\
\text { Regangan (Strain) }: \varepsilon=\frac{\Delta L}{L o} \times 100 \%=\frac{L-L o}{L o} \times 100 \% \\
\text { Modulus Elastis }: E=\frac{\sigma}{e}
\end{gathered}
$$




\section{ANALISA DAN PEMBAHASAN}

\subsection{Uji Radiografi}

Pengelasan SMAW menggunakan elektroda E6013 dengan variasi arus 80A, 100A,120A yang memiliki kualitas terbaik adalah pada arus 120 A. Pada arus 80 A ditemukan cacat las jenis Slag Inclusion yang cukup banya. Pada arus 100 A ditemukan cacat Inclomplete Penetration yang cukup banyak juga
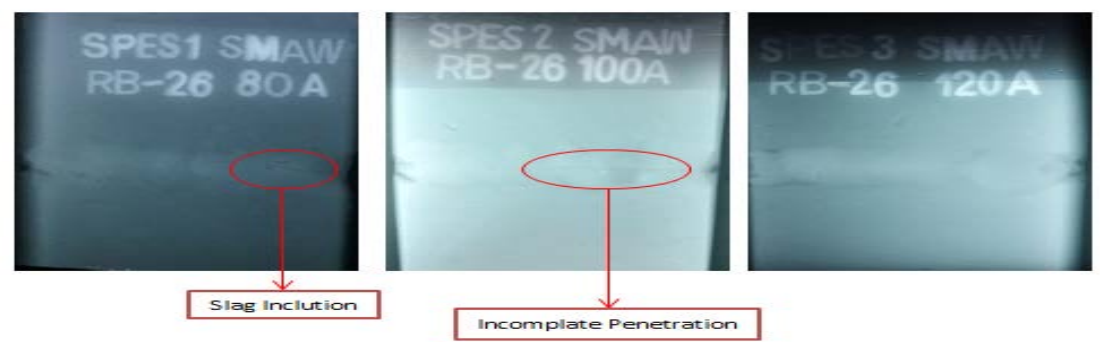

Gambar 3.1 Hasil Uji radiografi pengelasan SMAW dengan elektroda E6013

Pengelasan TIG menggunakan Filler TG-S50 dengan variasi arus 80A, 100A,120A yang memiliki kualitas terbaik pada arus 80A dengan sedikit cacat Cluster Porosity. Pada 100 A ada cacat Cluster Porosity yang cukup banyak. Pada 120 A ditemukan cacat las Incomplete Penetration dan Porosity yang cukup banyak

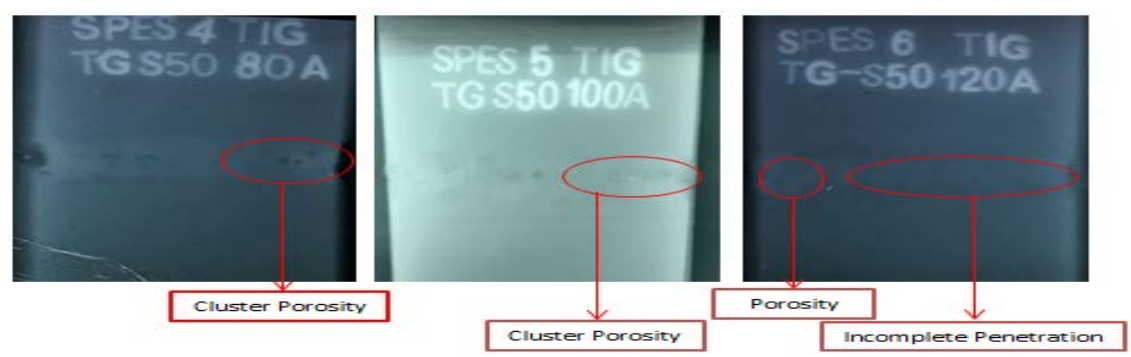

Gambar 3.2 Hasil Uji radiografi pengelasan TIG dengan Filler TG-S50

Dengan hasil pengujian tidak merusak (NDT) Radiography Test dengan jenis besi pengisi dan variasi $^{[3]}$

\subsection{Uji Kekerasan}

Untuk mengetahui kekerasan Baja AISI 1045 sebelum dan sesudah pengelasan pada daerah HAZ dan las. Penelitian ini menggunakan skala Brinell yang indentasi dan nilai kekerasannyanya dikonversikan dengan rumus BHN. 
Tabel 3.2 Hasil Pengujian Kekerasan Metode Brinell pada las SMAW dan TIG
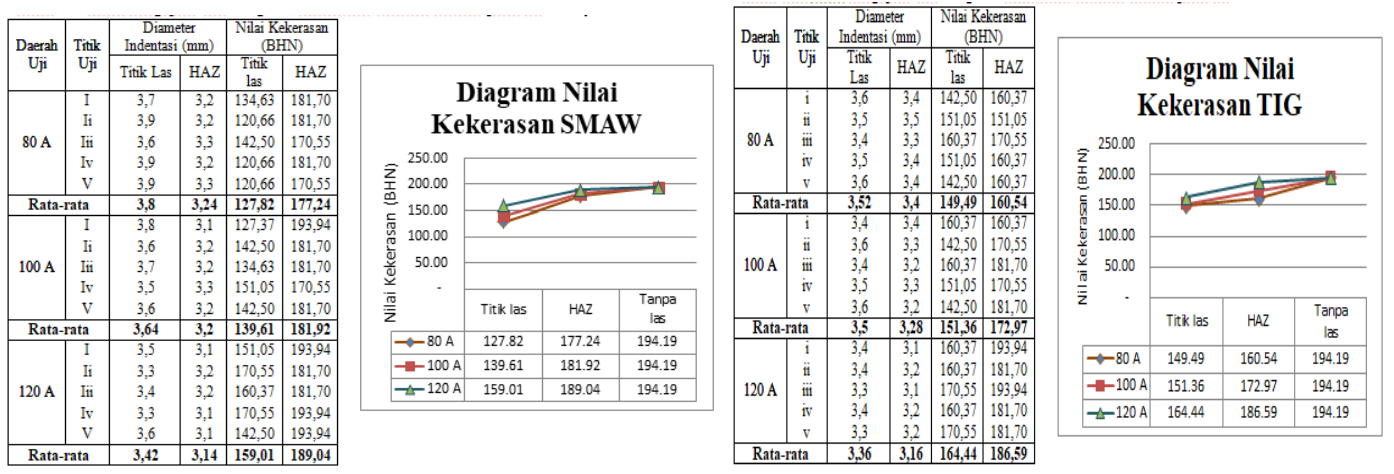

\subsection{Uji Tarik}

Pengujian tarik Baja AISI 1050 las TIG dan SMAW dengan kuat arus pengelasan 80A,100A,120A. Mengalami patah didaerah HAZ. Untuk angka kekuatan tarik Baja AISI 1050 yang dapat dilihat pada tabel di bawah ini.
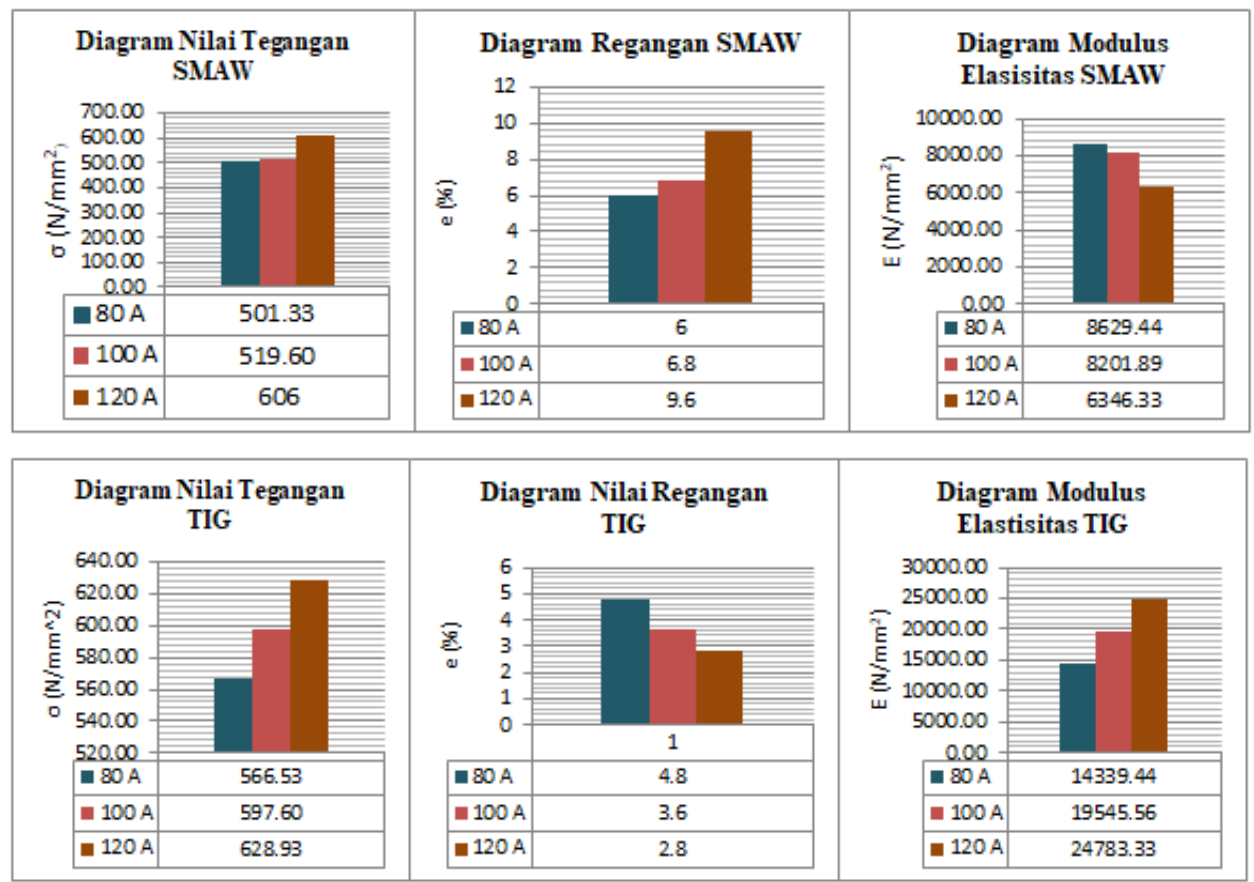

Gambar 3.4 Diagram uji tarik hasil pengelasan SMAW dan TIG

\subsection{Uji Struktur Mikro}

Pengujian mikrostruktur dilakukan dengan menggunakan "Reflected Metallurgical Microscope” dengan type Rax Vision No.545491, MM -10A,230V-50Hz. Ferrite adalah fasa larutan padat yang memiliki struktur BCC Ferrite ini akan terbentuk pada proses pendinginan 
lambat dari austenite baja hipoeutectoid.Sedangkan pearlite merupakan satu fas yang terbentuk dari gabungan dua fasa,yaitu ferrite dan cementite .

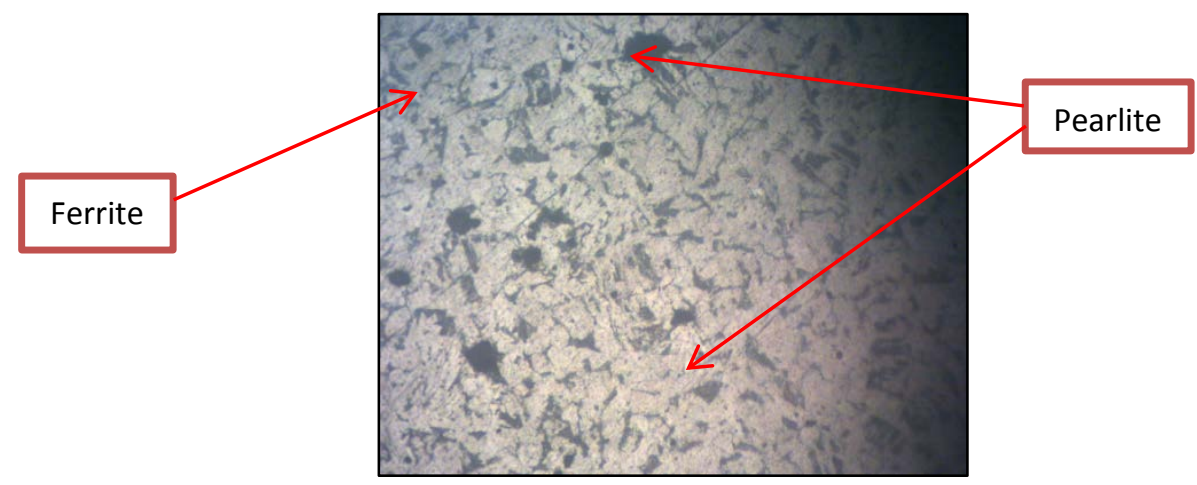

Gambar 3.5 gambar struktur mikro hasil pengelasan

Pengelasan SMAW dengan elektroda E6013 dan pengelasan TIG dengan filer TG-S50 bahwa semua spesimen terdapat ferrite, perlite dan cementit tetapi semakin besar arus yang di berikan pada pengelasan maka struktur ferrite dan perlite semakin mengikat. ${ }^{[6]}$ Struktur mikro cementit terbetuk dari kandungan unsur logam pengisi yang di padukan dengan base metal.

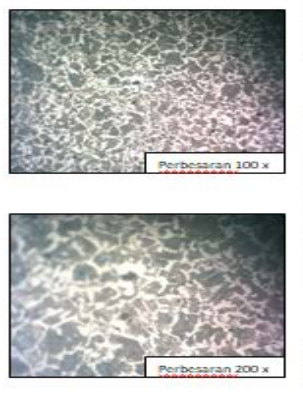

Struktur Mikro Tanpa Las

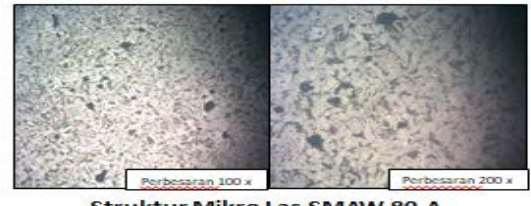

Struktur Mikro Las SMAW 80 A

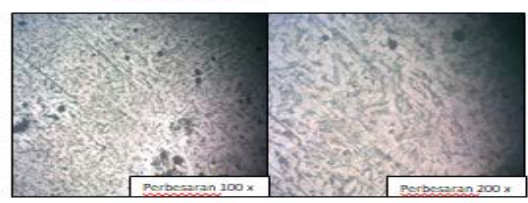

Struktur Mikro Las SMAW 100 A

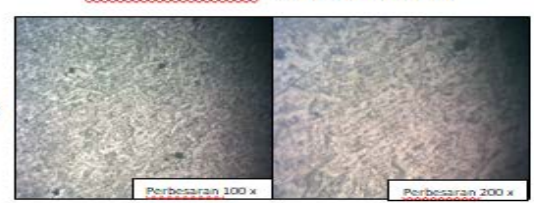

Struktur Mikro Las SMAW 120 A

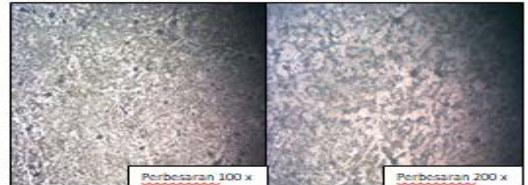

Struktur Mikro Las TIG 80 A

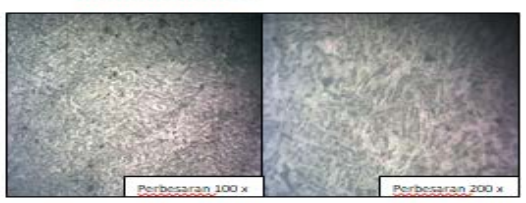

Struktur Mikro Las TIG 100 A

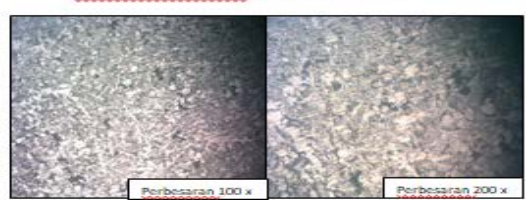

Struktur Mikro Las TIG 120 A

Gambar 3.5 Struktur mikro las SMAW dan TIG pada daerah las dan HAZ

\section{KESIMPULAN}

1. Pada pengelasan SMAW dan TIG selain jenis cacat yang disebutkan diatas, semua benda uji dinyatakan terkena cacat las jenis undercut. Disimpulkan bahwa arus yang optimum adalah pada 120 A dikarenakan pada arus 120 A minim ditemukan adanya cacat las pada kedua jenis las .

2. Pada jenis las SMAW kuat arus berbanding lurus meningkat pada nilai tegangan dan regangan nya sedangkan pada jenis las TIG kuat arus membuat perubahan nilai yang cukup berbeda dimana nilai tegangan dan nilai elastis berbanding terbalik 
- Nilai uji kekerasan tertinggi terdapat pada las TIG di variasi arus 120 A dengan nilai 164,44 BHN

- Nilai tegangan paling tinggi pada las TIG adalah spesimen dengan las $120 \mathrm{~A}$ yaitu sebesar 628,93 N/mm² tetapi untuk nilai regangan tertinggi terdapat pada variasi arus 80 A dengan 4,8\%. Dan nilai tegangan dan regangan paling tinggi pada las SMAW adalah spesimen dengan las 120 A yaitu sebesar $606 \mathrm{~N} / \mathrm{mm}^{2}$ dan regangan $9,6 \%$

3. Bentuk struktur mikro pada baja AISI 1050 sebelum pengelasan adalah struktur mikro Feritte, pada pengelasan TIG dititik las (filler) dan SMAW di titik las (elektroda) adalah perlitte, dan pada daerah HAZ (Heat Affective Zone) di SMAW maupun TIG struktur mikronya feritte,namun di daerah HAZ sudah mengalami perubahan (mengembang)

\section{REFERENSI}

[1] Alip, M. 1989. Teori dan Praktik Las. Jakarta: Departemen Pendidikan dan Kebudayaan.

[2] HarsonoWiryosumatro \& Thosie Okumura, Teknologi Pengelasan Logam. Pradanya Paramita, Jakarta Cetakan ke IX

[3] Novariandaru, A. 2014. Analisa Uji Visual dan Radiografi Pada Inspeksi Pengelasan Plat Baja Migas Cepu. Yogyakarta: Universitas Gadjah Mada.

[4] https://www.azom.com/article.aspx?ArticleID=9153

[5] Groover, Mikell P. 1996. Fundamental Of Modern Manufacturing,Material, Proses And System. Penerbit Prentice-Hall Inc. USA.

[6] Metallography, Structures, and Phase Diagrams, Vol 8, Metals Handbook, 8th ed., American Society for Metals, 1973. 